\title{
REVIEW
}

\section{Design and Implementation of Data Management System for Light- ning Protection Inspection Based on Android}

\author{
Yinan Xia ${ }^{1}$, Geyi Wen ${ }^{1}$, Fan Zhou ${ }^{2}$, Gang Chen ${ }^{3}$, Peng Wang ${ }^{4}$ \\ 1. Nanjing University of Information Science \& Technology, Nanjing, Jiangsu, 210044, China \\ 2. Pingliang Meteorological Administration, Pingliang, Gansu, 744000, China \\ 3. Zhangqiu Meteorological Administration, Jinan, Shandong, 250200, China \\ 4. Jiyang Meteorological Administration, Jinan, Shandong, 251400, China
}

\author{
ARTICLE INFO \\ Article history \\ Received: 9 August 2019 \\ Revised: 25 August 2019 \\ Accepted: 10 October 2019 \\ Published Online: 16 October 2019 \\ Keywords: \\ Safety inspection for lightning protection de- \\ vices \\ Mobile applications \\ Professional equipment \\ Information management
}

\section{Preface}

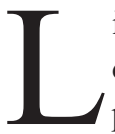
ightning is "one of the ten most serious natural disasters" that affect human life, and is also "a public hazard in the electronic age" ${ }^{,[1]}$. Lightning disasters occur frequently in our country, as a result of which the casualties and economic losses are on the rise year by year, and the social impact is also increasing rapidly ${ }^{[2]}$. With the continuous and in-depth development of lightning-related disasters prevention work, local meteorological departments are attaching

\begin{abstract}
In order to ensure the safety of buildings, equipment, personnel, property and production, to prevent or mitigate the disasters caused by lightning and static electricity, and to avoid the occurrence of serious lightning accidents, lightning protection inspection (acceptance) is of great significance. At present, in the process of inspection (acceptance) of lightning protection devices, there are following problems: professional and technical equipment for inspection is various and with different performances; the market demand for lightning-proof safety inspection is large, and entrusted units are increasing; the inspection process is difficult to be accurately obtained anytime and anywhere. Therefore, it is proposed to adopt technology of mobile application, wireless network transmission and computer software development to design and develop a data management system for lightning protection inspection based on Android, so as to realize the functions like real-time and comprehensive information management of professional lightning-proof inspection devices and entrusted units and establishment of electronic files for lightning-proof inspection of all projects.
\end{abstract}

more importance to the information construction work of lightning prevention and disaster reduction management departments ${ }^{[3]}$, and are also developing software systems out of their own business needs. However, most of the systems are limited to the business management within the office and do not have the ability to process the safety inspection data of lightning-proof devices anytime and anywhere ${ }^{[4]}$, moreover, the business functions realized by the software are too single to grasp the accuracy of information from the information sources of lightning-proof devices.

\footnotetext{
*Corresponding Author:

Yinan Xia,

Correspondence Address: Nanjing University of Information Science \& Technology, Nanjing, Jiangsu, 210044, China;

Research direction: meteorological observation;
}

Email:294911884@qq.com. 


\section{Research Content and Technical Routes of Sys- tems}

\subsection{Research Content}

Using hand-held terminal systems and wireless channels to assist staff working on lightning-proof devices safety inspection to use wireless terminals at anytime and anywhere: to establish electronic files of professional lightning-proof inspection devices and realize functions such as inquiry and editing; to establish the electronic files of entrusted units and realize the functions of inquiry and editing; to establish the electronic files of lightning prevention and inspection business for all projects and realize the functions of inquiry and editing. The framework of system functions is shown as below:

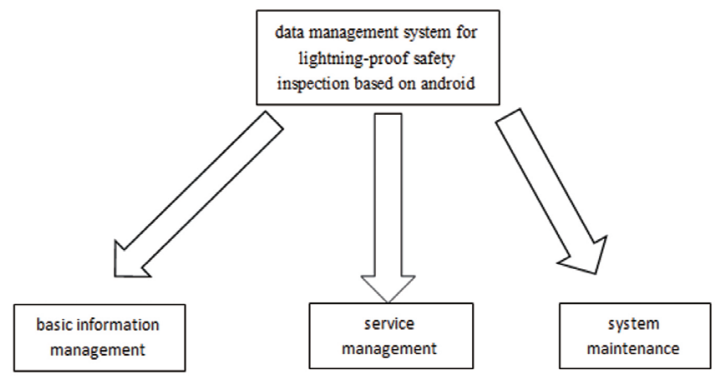

\subsection{Technical Routes}

Android is a kind of operating system based on the freedom of Linux and open source code, which is mainly used in mobile devices like smart phones and tablets, and it is led and developed by Google and Open Handset Alliance ${ }^{[5]}$. Android's Linux kernel control includes Security, Memory Management, Process Management, Network Stack, and Driver Model, etc. ${ }^{[6]}$. The technology architecture of Android ${ }^{[7]}$ is shown as following figure:

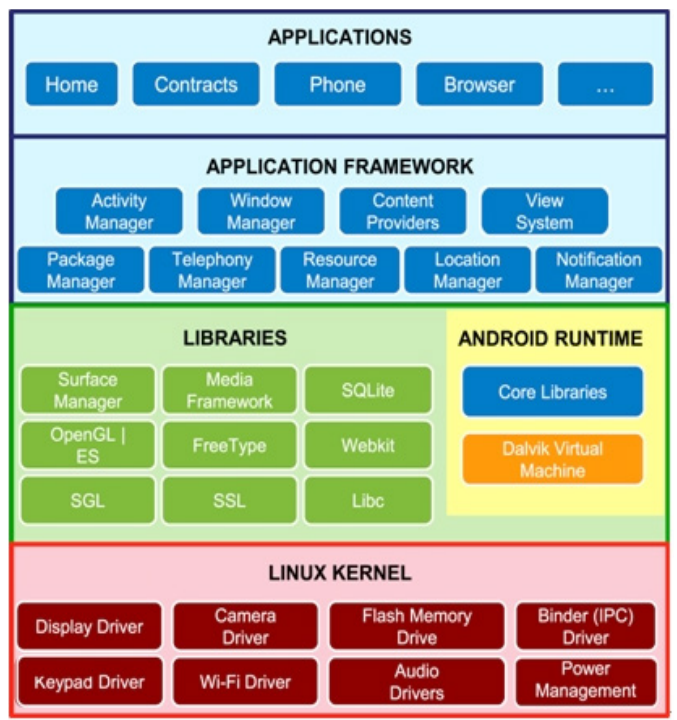

\section{Implementation and Application of Key System Functions}

In the functional analysis, the basic information management service, business management service and system maintenance and management service will be designed using UML modeling language, and the use case diagram of the service and the use case specification table of the core service will be given. Android-based data management system for lightning-proof safety inspection can operate the analysis function at the mobile phone end. The users with operation authority in this system are data processing personnel working on lightning-proof safety inspection.

\subsection{Management and Analysis of Entrusted Units of Lightning Prevention Testing and Technical Equipment}

Lightning prevention data processing personnel can query, add, edit and delete the information of the entrusted units, and can also carry out similar operations on the information of professional lightning-proof equipment. Use case diagram of basic information management service is shown as following figure:

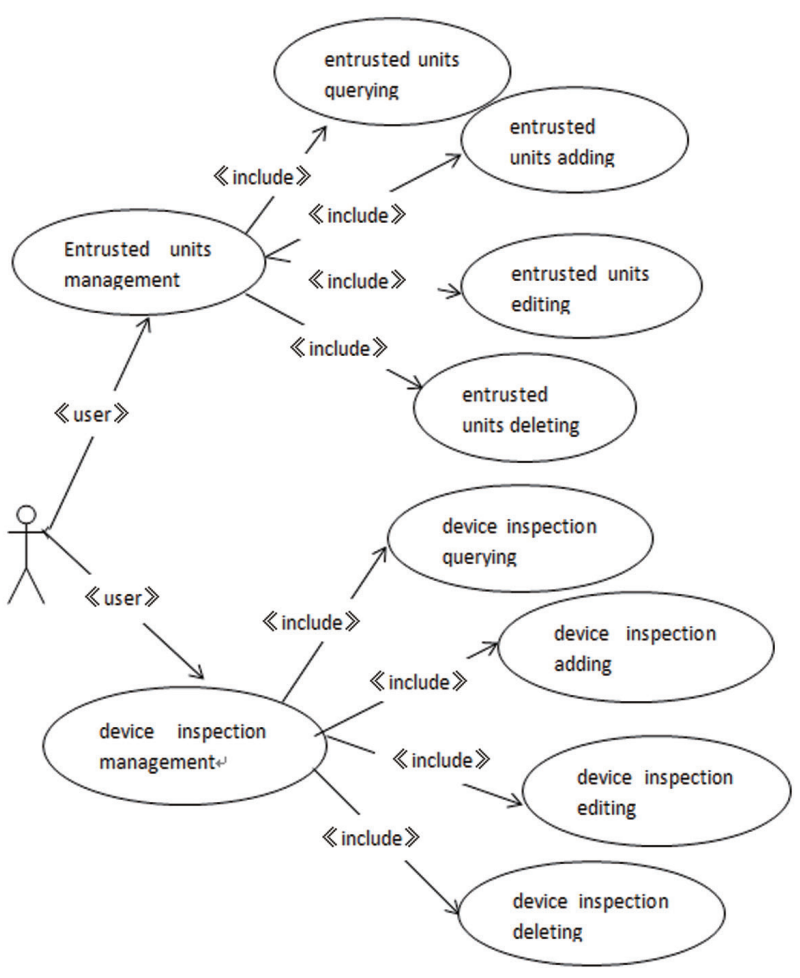

(1) Entrusted units management: Operations such as Entrusted Units Query, Entrusted Units Add, Entrusted Units Edit and Entrusted Units Delete can be performed. When querying the information of the entrust- 
ed units, the company information needs to be retrieved according to the company name and contact person, after which the contact phone number, zip code, and address can be retrieved.

(2) Management of lightning-proof inspection technology and equipment: Operations like querying, adding, editing and deleting lightning-proof inspection technology and equipment can be carried out. Information such as instrument name, model and number shall be filled in when adding lightning-proof inspection technology and equipment. After executing deleting operation, the inspection information will disappear in the database.

\subsection{Business Management Analysis of Lightning Protection Testing}

The functions analyzed in business management include the management before, in and after lightning protection testing.

(1) Management before lightning protection testing: operations such as detection, details query, addition, editing and deletion of lightning protection before testing could be carried out. It is necessary to record the entrusting unit, unit address, zip code, lightning protection category, contact person, contact phone number and entrustment agreement number when starting the operation.

\begin{tabular}{|c|c|c|c|}
\hline Use case name & $\begin{array}{l}\text { Lightning Protection Management } \\
\text { to Be Detected }\end{array}$ & Use case number & SafetyInspectionUT-02 \\
\hline Participating member & \multicolumn{3}{|c|}{ Lightning protection data processor } \\
\hline Use case analysis function & \multicolumn{3}{|c|}{ Detection, inquiry, and editing of lightning protection before being tested } \\
\hline Preconditions & \multicolumn{3}{|c|}{$\begin{array}{l}\text { (1) The functions of the original data acquisition and processing system for the safety detection of lightning } \\
\text { protection devices based on mobile applications can be executed normally. } \\
\text { (2) The lightning protection data processing personnel log into the original data acquisition and processing } \\
\text { system of lightning protection device safety detection based on mobile application. }\end{array}$} \\
\hline Basic event flow & \multicolumn{3}{|c|}{$\begin{array}{l}\text { (1) When lightning protection data processing personnel request for lightning protection to be detected, users } \\
\text { need to query information according to the entrusting unit and the contact person, which includes the entrust- } \\
\text { ing unit, contact person, unit address, contact telephone number, zip code, entrustment agreement number and } \\
\text { testing status. } \\
\text { (2) Lightning protection data processing personnel need to input information such as entrusting unit, contact } \\
\text { person, unit address, contact phone number, etc. according to system prompts when requesting to the addition } \\
\text { operation in lightning protection testing. After recording, user select save to complete. } \\
\text { (3) When requesting the lightning protection detection editing operation, the lightning protection detection } \\
\text { information shall be located according to the entrusting unit and the contact person firstly, and then the located } \\
\text { lightning protection detection information shall be changed and saved after the change is completed. }\end{array}$} \\
\hline Abnormal & \multicolumn{3}{|c|}{ Data update speed is slow when editing lightning protection detection. } \\
\hline
\end{tabular}

The use case specification table of lightning protection management before testing is shown in the following table.

(2) Management in lightning protection testing: the operation of inquiring including inquiring details can be carried out. The entrusting unit, unit address, zip code, weather condition, lightning protection category, contact person, contact number, detection date, ground condition, entrustment agreement number, etc can be inquired in the details function in lightning protection testing.

(3) Lightning protection detected management: it can detected inquiry and lightning protection detected inquiry details.

(4) Lightning protection pending audit management: pending audit inquiry, pending audit inquiry details and pending audit printing operations can be carried out.

(5) Lightning protection detection management: new detection operations can be carried out.

\subsection{Account Configuration and System Mainte- nance}

(1) Account information maintenance: information inquiry, information addition, editing, deletion and password reset can be performed.

(2) Role management: Role query, addition, editing, deletion and empowerment can be performed. Different roles have different operation permissions. When editing role information, the name and comments of the role need to be changed. Before deleting a role, one should query the role first, find the role that needs to be deleted, and then perform the deletion operation.

(3) Resource management: resource query can be performed. Information in the resource management area includes resource name, URL, whether to display menu, menu type, sorting and so on.

\section{Conclusion}

Through the design and implementation of each functional module of the Android-based lightning protection safety detection data management system, real-time and comprehensive systematic management is realized for those specialized technical equipment with complex models and different performances and the large number of 
lightning protection detection commissions. A specific lightning protection detection business process can be detected by users accurately at any time and anywhere, and users also can audit, add information, etc. This system reduces the waste of paper, improves the work efficiency of the detection personnel, and helps the lightning protection safety supervision department to check and repair defects, and thus avoiding the occurrence of lightning disasters and bring certain social benefits

\section{References}

[1] Ma Ming, Lu Weitao, Zhang Yijun. Characteristics of Lightning Disaster in China from 1997 to 2006 [J]. Journal of applied meteorological science, 2008, 19 (4): 394-395.

[2] Miao Weibin, Meng Xiangfei, Sun Jinhua. Lightning Disaster Investigation and Appraisal Software System and Its Application [J]. Qixiang Science and
Technology, 2010,38 (6): 794-796

[3] Zhang Huiliang, Zhang Weibin, Lu Shan Ying, etc. Zhejiang province lightning protection device testing business specification [R]. 2012: 2 - 20.

[4] Yan jingdong. Design and Implementation of Information Management System for Building Lightning Protection Device Detection [D]. Jinan, Shandong University, 2012.

[5] carbon pool. Design and Research of Embedded Handheld Terminal Based on GPRS Network [D]. Wu Han: Wuhan University of Technology, 2005.

[6] Hu Wen, Cao Xiaole. Research on ARM-based Mobile Handheld Terminal [J]. Journal of Harbin Commercial University (Natural Science Edition), 2007,23 (5): 540-541.

[7] Zong Tao. Design and Implementation of Structural Security Model Based on Trusted Computing [J]. Computer Engineering, 2012,38(20):89-92. 